\title{
NEUROLOGICAL COMPLICATIONS AND BACILLE CALMETTE-GUERIN VACCINATION STATUS OF CHILDREN WITH TUBERCULOUS MENINGITIS: A TERTIARY CARE HOSPITAL EXPERIENCE
}

\section{Bibi Aalia ${ }^{1,2}$, Syed Sajid Hussain Shah ${ }^{2}$}

\begin{abstract}
OBJECTIVE: To assess for the neurological complications and Bacille CalmetteGuerin (BCG) vaccination status of children with tuberculosis meningitis (TBM).

METHODS: This retrospective study was conducted in Ayub Teaching Hospital, Abbottabad, Pakistan. Data of diagnosed case of TBM who received antituberculous therapy from 2017 to 2020 was retrieved from records. Records of children, aged 6 months to 10 years of either gender were included and vaccination status was documented along with CT scan findings. Neurological complications in hospital and outcome were recorded as discharge, expiry and transfer to other hospital.
\end{abstract}

RESULTS: Out of 40 patients, 17 (42.5\%) were males and 23 (57.5\%) females. Age ranged from 6 months to 8 years with mean age of $2.81 \pm 2.29$ years. Weight ranged from 5 to $24 \mathrm{~kg}$ and mean weight was $10.36 \pm 4.96 \mathrm{~kg}$. About $72.5 \%$ patients were $<5$ years of age. About $47.5 \%(n=19 / 40)$ patients were not vaccinated for BCG. Primary source of tuberculosis in close contacts was identified in $35 \%(n=14 / 40)$ patients. Common findings on CT scan were hydrocephalus $(35.0 \% ; n=14 / 40)$ \& cerebral infarct $(15.0 \% ; n=6 / 40)$. The common complication observed were hydrocephalus $(35 \% ; n=14 / 40)$, acute stroke (20\%; $n=8 / 40)$, cranial nerve palsies $(12.5 \% ; n=5 / 40)$, seizure disorder (I2.5\%; $n=5 / 40)$. Mortality rate was $2.5 \%(n=1 / 40)$. Only $35.7 \%(5 / 14)$ of patients with hydrocephalus and no patient with stroke or seizures were fully vaccinated.

CONCLUSION: Hydrocephalus \& stroke are the most common complication in children with TBM. Neurological complications were observed more commonly in children who were either not vaccinated or partially vaccinated for BCG.

KEY WORDS: Tuberculosis (MeSH); Meningitis (MeSH); Immunization (MeSH); Hydrocephalus (MeSH); Stroke (MeSH).

THIS ARTICLE MAY BE CITED AS: Aalia B, Shah SSH. Neurological complications and Bacille Calmette-Guerin vaccination status of children with tuberculous meningitis: a tertiary care hospital experience. Khyber Med Univ J 2020; I 2(4): 305-9. DOI: I0.35845/kmuj.2020.2043I.

\section{INTRODUCTION}

$\mathrm{T}$ uberculosis (TB) in this era is still widespread especially in third world countries like Pakistan. According to World Health Organization (WHO) Global tuberculosis report 2019, in 2018 about 10 million new cases of TB were reported worldwide and out of these I.I million were children.' Tuberculous meningitis (TBM) accounts for $1-2 \%$ of active tuberculosis but even with appropriate treatment, it is associates with neurologic sequelae and death. ${ }^{2,3}$ In children, studies have shown that TB has different clinical manifestations and history as compared to adults. As children tend to have high risk of progressive disease and present with disseminated TB including TBM. ${ }^{4}$

Though TB in children is reported about $10-20 \%$ and may rise to $40 \%$ in TB endemic area yet it may be underestimated. ${ }^{5}$ TBM in children have high morbidity and mortality. ${ }^{6}$ Outcome
I. Department of Pediatrics, Khyber Medical University Institute of Medical Sciences (KMU-IMS), Kohat, Pakistan.

2. Department of Pediatrics, Ayub Teaching Hospital, Abbottabad, Pakistan. Email凶: dr.alia87@hotmail.com Contact \#: +92-333-5153856

$\begin{array}{ll}\text { Date Submitted: } & \text { June 06, } 2020 \\ \text { Date Revised: } & \text { October 24, } 2020 \\ \text { Date Accepted: } & \text { November 09, } 2020\end{array}$

is poor if timely diagnosis and treatment is not taken appropriately. ${ }^{7}$ Diagnosis of TBM in children requires high index of suspicion as CSF findings are with in normal limits in $30 \%$ of patients. ${ }^{8}$ In developing countries due to lack of advance investigations even in tertiary care hospitals diagnosis of TBM can be delayed which may adversely affects the outcome. ${ }^{9}$ Neurological disable children are not only difficult to manage in hospital but also needs continuous care by parents. In Pakistan, local literature is available regarding TBM but have not correlated TBM severity with the Bacille Calmette-Guerin (BCG) vaccination. This study results will emphasize for more rationale coverage of $B C G$ vaccination in children of developing countries to prevent complications of TBM. This study was done to describe the neurological complications and vaccination status of children with TBM

\section{METHODS}

This retrospective study has been done in Paediatric B ward of Ayub Teaching Hospital, Abbottabad, Pakistan. Data of children with TBM has been retrieved from the patient records from April, 2017 till March, 2020 over 3 years after approval from institutional review board. Records of patients who presented and got admitted in Paediatric $B$ ward with diagnosis of TBM and started on Anti-tuberculous 
TABLE I: FINDING ON CEREBRO-SPINAL FLUID (CSF) EXAMINATIONS

\begin{tabular}{|l|c|c|c|c|c|c|}
\hline \multicolumn{2}{|l|}{} & $\begin{array}{c}\text { CSF sugar } \\
(\mathbf{m g} / \mathbf{d l})\end{array}$ & $\begin{array}{c}\text { Lymphocytes } \\
\text { (percentage) }\end{array}$ & $\begin{array}{c}\text { CSF Protein } \\
(\mathbf{m g} / \mathbf{d l})\end{array}$ & $\begin{array}{c}\text { Polymorphs } \\
(\text { percentage })\end{array}$ & $\begin{array}{c}\text { CSF } \\
(\text { cells/cmm })\end{array}$ \\
\hline Median & 42.94 & 72.50 & 170.84 & 27.50 & 110.00 \\
\hline Minimum & 4 & 4 & 24 & 0 & 2 \\
\hline Maximum & 117 & 100 & 678 & 96 & 4000 \\
\hline \multirow{3}{*}{ Percentiles } & 25 & 24.25 & 69.63 & 74.00 & 10.00 & 34.00 \\
\cline { 2 - 7 } & 50 & 42.94 & 72.50 & 170.84 & 27.50 & 110.00 \\
\cline { 2 - 7 } & 75 & 60.75 & 90.00 & 181.75 & 30.38 & 533.06 \\
\hline
\end{tabular}

TABLE II : PRIMARY SOURCE OF TUBERCULOSIS IN CLOSE CONTACTS

\begin{tabular}{|l|c|c|}
\hline \multicolumn{1}{|c|}{ Primary case } & Frequency & Percent \\
\hline Parents & 6 & 15.0 \\
\hline Grandparents & 5 & 12.5 \\
\hline Uncle/ aunt & 2 & 5.0 \\
\hline Siblings & $\mathrm{I}$ & 2.5 \\
\hline Not known & 26 & 65.0 \\
\hline Total & 40 & 100.0 \\
\hline
\end{tabular}

TABLE III: FINDINGS ON COMPUTED TOMOGRAPHIC (CT) SCAN

\begin{tabular}{|l|c|c|}
\hline \multicolumn{1}{|c|}{ CT scan finding } & Frequency & Percent \\
\hline Hydrocephalus & 14 & 35.0 \\
\hline Infarct & 6 & 15.0 \\
\hline Tuberculoma & 2 & 5.0 \\
\hline Meningeal enhancement & 2 & 5.0 \\
\hline Normal study & 4 & 10.0 \\
\hline Not done & 12 & 30.0 \\
\hline Total & 40 & 100.0 \\
\hline
\end{tabular}

TABLE IV: COMPLICATIONS OBSERVED AT THE TIME OF DISCHARGING THE PATIENT

\begin{tabular}{|l|c|c|}
\hline \multicolumn{1}{|c|}{ Complications } & Frequency & Percent \\
\hline Hydrocephalus & 14 & 35.0 \\
\hline Hemiplegia/ & 8 & 20.0 \\
\hline Seizures & 5 & 12.5 \\
\hline Cranial nerve palsies & 5 & 12.5 \\
\hline Hearing loss & 2 & 5.0 \\
\hline Aspiration pneumonia & $\mathrm{I}$ & 2.5 \\
\hline Nil & $\mathrm{II}$ & 27.5 \\
\hline
\end{tabular}

Treatment (ATT) were included in study. Patients, who were known case of TBM taking ATT or completed the treatment before April, 2017 were not included. Patients known case of developmental delay due to any etiology, syndromic children, seizure disorders were also not included in the study. Children aged from 6 month to 10 years of either sex were included. Vaccination status was documented as up to date vaccinated if vaccine schedule was complete according to Expanded
Programme on Immunization (EPI) vaccine card. If missed any dose according to age then taken as partially vaccinated and if none of vaccine given apart from polio drop then taken as not vaccinated. BCG scar of BCG vaccine given as birth also documented. History of contact was documented if known otherwise unknown was assigned for primary case. Patient age, weight, sex, vaccination status, BCG scar, cerebrospinal fluid (CSF) cell count, percentage of polymorph count and lymphocyte count, CSF sugar and protein documented on specific proforma. Findings of computed tomography (CT) scan brain were also documented. Patient's outcome was assessed in hospital. Discharge, expiry and transfer to other hospital were taken as outcome. Complications at time of discharge from hospital were documented. Data was analyzed using SPSS 20.

\section{RESULTS}

During the study period, forty patients were diagnoses as case with TBM. Out of 40 patients, $17(42.5 \%)$ were male and $23(57.5 \%)$ were females. Age ranged from 6 months to 8 years with mean age of $2.8 \mathrm{I} \pm 2.29$ years. Weight ranged from 5 to $24 \mathrm{~kg}$ with mean weight of $10.36 \pm 4.96 \mathrm{~kg}$. Majority of patients $(n=18 / 40 ; 45 \%)$ were less than 2 years, I I ( $27.5 \%)$ patients were from 2 to 5 years and II (27.5\%) patients were more than 5 years of age.

Vaccination status showed that II $(27.5 \%)$ were fully vaccinated (up to date), 10 (25\%) were partially vaccinated and $19(47.5 \%)$ patients were not vaccinated. BCG scar was present in only $10(25 \%)$ patients. Cerebrospinal fluid findings are shown in Table I. History of TB was present in family of $35 \%(n=14 / 40)$ patients (Table II).

Outcome as "discharge from hospital" was documented in 38 (95\%) patients. Only one $(2.5 \%)$ patient expired and one patient $(2.5 \%)$ transferred to another hospital. CT scan brain was not done in $12(30 \%)$ patients. The most common finding on the CT scan done was hydrocephalus $(n=14)$ [Table III].

The common complication observed were hydrocephalus ( $35 \% ; n=14 / 40$ ), acute stroke $(20 \% ; n=8 / 40)$, cranial nerve palsies ( $12.5 \% ; n=5 / 40)$ [Table VI]. There was no complication in II (27.5\%) patients at time of discharge from hospital. One patient with coma/decerebrate posture had aspiration pneumonia and expired. Mortality rate was $2.5 \%(n=1 / 40)$. Three patients with hydrocephalus required ventriculoperitoneal shunt. 
The children who were not vaccinated had more complications. All three patients who required VP shunt were not vaccinated. Only $35.7 \%(n=5 / 14)$ of patients with hydrocephalus and no patient with stroke or seizures were fully vaccinated. (Table V)

\section{DISCUSSION}

In our study, almost half $(47.5 \%)$ of TBM patients were not vaccinated for BCG. The common complication observed were hydrocephalus (35\%), acute stroke $(20 \%)$, cranial nerve palsies $(12.5 \%)$ and seizure disorder (I $2.5 \%)$. Mortality rate was $2.5 \%$ $(n=1 / 40)$. Common findings on CT scan were hydrocephalus (35.0\%) \& cerebral infarct (15.0\%). Majority of patients with hydrocephalus, stroke and seizures were either not vaccinated or partially vaccinated.

Pakistan is one of the endemic countries with TB and included in list of top 8 countries having TB, according to WHO report 2019. Among the eight countries which account for $66 \%$ of new cases of TB, Pakistan accounts for $6 \%$ of new TB cases.' The presentation of TB in children with central nervous system involvement is in form of TBM, post TBM hydrocephalus. Also the tuberculoma can present as space occupying lesion. ${ }^{10}$

Nataprawira HM et al" did one retrospective/prospective study and included 29 children with TBM and follow them. In their 16 were male and 13 were female. About $3 / 4$ of patients had delayed mental and neurological development. While in our study majority were females and $60 \%$ patient had neurological complications which is near to their study. Hearing loss was also one of major complication in
Nataprawira HM, et al. study; while in our study we only observed it in two (5\%) patients. Faried A, et al. ${ }^{12}$ in one of case series done in Indonesia reported 7 children with TBM and the most common complication was hydrocephalus with and without tuberculoma. In our study the most frequent complication was hydrocephalus in $35 \%$ of patients. The CT finding showing tuberculoma was in $5 \%$ patients.

$B C G$ vaccine protection against $T B$ varies and it has been reported between 0 to $80 \%$ as shown by different studies. $^{13}$ In our study only $27.5 \%$ patients were fully vaccinated and $25 \%$ patients were partially vaccinated. Out of I I patients who were vaccinated up to date, 4 patients did not have BCG scar. In partially vaccinated children 7 patients out of 10 were not having BCG scar.

Afridi JK, et al. ${ }^{14}$ studied the clinical features for diagnosis of TBM in children in one of teaching hospital of $K P$, Pakistan. The majority of patient having TBM was less than five years of age and accounted for $82 \%$ of total patients. In our study $72.5 \%$ patients were under five years of age which affirms the findings of Afridi JK, et al. study findings. ${ }^{14}$ The literature also documented that children with younger age are more associated with TBM. ${ }^{15}$ Rashid A, et al. ${ }^{16}$ in one of the tertiary care hospitals of Pakistan studied Tuberculosis among admitted children. In their study majority of females $(60.57 \%)$ were having TB. In comparison in our study $57.5 \%$ with TBM were females. In their study TBM was present in $13.14 \%$ patients. Their study recommended that the index case should be traced. In our study in $65 \%$ of patients family history of TB was not known and only was traced in $35 \%$ of patients.

Qureshi S, et al. ${ }^{17}$ studied the diagnostic modalities in children with TB. In their study the majority of patients $(54.9 \%)$ were also female; this is as compare to our study having $57.5 \%$ females with TBM. Khan IM, et al. ${ }^{18}$ in their research letter included 34 children from northern Pakistan. Out of 34 patient, 26 patients had TBM. Females were $58.8 \%$ as like in our study where females were $57.5 \%$. In literature we could not find the exact reason for increased incidence in females but may be due to social reason that female are more malnourished and prone for disease. In their study $52.9 \%$ cases were having known TB index case, while in our only $35 \%$ patients had family history of TB. Majority $(57.5 \%)$ of patients were not vaccinated with no BCG scar while in our study $72.5 \%$ were either not vaccinated or partially vaccinated with BCG scar only present in 3 out of 10 patients who were partially vaccinated.

Anjum $\mathrm{N}$, et al. ${ }^{19}$ in their study included 40 patients with TBM. In contrast to our study, their study included males $(62.5 \%)$ in majority. Like our study (72.5\%), in Anjum N, et al. study majority $(65 \%)$ of patient were less than 5 years of age. Morality in our study was $2.5 \%$ while in their study the mortality was $5 \%$. All the survivors in their study were having neurological issues while in our study only $40 \%$ patients were having neurological issues. Miftode EG, et al. $^{20}$ retrospective analysis of Paediatric and adult patients who were diagnoses with TBM. In their analysis 77 children were included. Index case was identified in $30 \%$ of patients while in our study $35 \%$ patients had a family history of TB in close contacts. Cranial nerve palsies were observed in $10 \%$ patients

TABLE V: VACCINATION STATUS VS COMPLICATIONS OBSERVED

\begin{tabular}{|l|c|c|c|c|c|c|c|}
\hline $\begin{array}{c}\text { Vaccination status } \\
(\mathbf{n}=40)\end{array}$ & $\begin{array}{c}\text { Nil } \\
(\mathbf{n}=1 \mathrm{II})\end{array}$ & $\begin{array}{c}\text { Hydrocephalus } \\
(\mathbf{n}=14)\end{array}$ & $\begin{array}{c}\text { Hemiplegia } \\
(\mathbf{n}=8)\end{array}$ & $\begin{array}{c}\text { Seizures } \\
(\mathbf{n}=\mathbf{5})\end{array}$ & $\begin{array}{c}\text { Nerve palsies } \\
(\mathbf{n}=\mathbf{5})\end{array}$ & $\begin{array}{c}\text { Hearing loss } \\
(\mathbf{n}=\mathbf{2})\end{array}$ & $\begin{array}{c}\text { Aspiration } \\
\text { pneumonia }(\mathbf{n}=1)\end{array}$ \\
\hline $\begin{array}{l}\text { Up to date } \\
(\mathrm{n}=\mathrm{II})\end{array}$ & $\begin{array}{c}4 \\
(36.4 \%)\end{array}$ & $5(35.7 \%)$ & 0 & 0 & $\begin{array}{c}2 \\
(40 \%)\end{array}$ & 0 & 0 \\
\hline $\begin{array}{l}\text { Partial vaccinated } \\
(\mathrm{n}=10)\end{array}$ & $\begin{array}{c}\mathrm{I} \\
(9.1 \%)\end{array}$ & $5(35.7 \%)$ & $2(25 \%)$ & $2(40 \%)$ & $\begin{array}{c}1 \\
(20 \%)\end{array}$ & 0 & $1(100 \%)$ \\
\hline $\begin{array}{l}\text { Not vaccinated } \\
(\mathrm{n}=19)\end{array}$ & $\begin{array}{c}6 \\
(54.5 \%)\end{array}$ & $4(28.6 \%)$ & $6(75 \%)$ & $3(60 \%)$ & $\begin{array}{c}2 \\
(40 \%)\end{array}$ & $2(100 \%)$ & 0 \\
\hline
\end{tabular}


while in our study $12.5 \%$ patients were having cranial nerve palsies. Permanent neurological deficits were observed in $23 \%$ children while in our study patients it was $20 \%$.

Mihailidou $\mathrm{E}$, et al. ${ }^{21}$ done study in Greece. Their retrospective study included 43 children with TBM but $63 \%$ of their patients were not vaccinated at all. In comparison, $47.5 \%$ of our patients were not vaccinated at all. Index case was identified in $42 \%$ of cases while in our study $35 \%$ of patient's primary source was identified. Their expiry was $5 \%$ in comparison to our study expiry rate of $2.5 \%$. Permanent neurological deficit was observed in $14 \%$ cases, as it was $20 \%$ in our patients.

There are limitations in our study. The study was retrospective. Other limitation was that the outcome was only assessed in hospital. For better understanding of impact of TBM on central nervous system, long term follow-up is required. There was family history of TB in $35 \%$ of cases. If some child is diagnosed with TB involving any system, whole of the family should be screened for the contact, if index case is not known. No family screening was possible for this study.

\section{CONCLUSION}

Hydrocephalus, stroke, seizures \& cranial nerve palsies are the most common complication in children with TBM. Majority of children were either not vaccinated or partially vaccinated. Neurological complications were more commonly observed in children having no or partial vaccination for $B C G$.

\section{RECOMMENDATIONS}

TBM in children is very serious condition in children with lifelong impact on the development and neurological outcome. Multicenter studies with long term follow up should be done for better understanding of TBM impact in our population. Community and parents should be encouraged for the vaccination of children starting with BCG vaccination at birth.

\section{REFERENCES}

I. World Health Organization (WHO). Global tuberculosis report 2019. [Accessed on: May 17, 2020]. Available from URL: https://www.who.int/tb/publication s/global_report/en/

2. Shah I, Pereira N. Tuberculous Meningitis in Children: a Review Article. Curr Infec Dis Rep 2020;22: I I. DOI: 10.1007/s I 1908020-0720-7.

3. Wang DM, Li QF, Zhu M, Wu GH, Li $\mathrm{X}, \mathrm{Xu} \mathrm{YH}$, et al. Epidemiological, clinical characteristics and drug resistance situation of culture confirmed children TBM in southwest of China: a 6-year retrospective study. BMC Infect Dis 2020;20(1):318. DOI: 10.1186/ s| 2879-020-0504|-3.

4. Garg RK. Tuberculous meningitis. Acta Neurol Scand 2010;122: 75-90. DOI: 10.1 I II/j.1600-0404. 2009.01316.x.

5. Marais BJ, Schaaf HS. Childhood tuberculosis: an emerging and previously neglected problem. Infect Dis Clin North Am 2010;24:717-49.

6. Daniel BD, Grace GA, Natrajan M. Tuberculous meningitis in children: Clinical management \& outcome. Indian J Med Res 2019;150(2):II730. DOI: $10.4103 / \mathrm{ijmr}$.IJMR 786_17.

7. Nataprawira HM, Wonoputri N. Obstacles facing tuberculosis treatment in children from a developing country: a hospital based study. Am J Epidemiol Infect Dis 20I4;2(I):8-I2. DOI: 10.1269I/ ajeid-2-I-2.

8. Anwar M, Ahmad A, Ahmad F, Mazhar A. Modified Kenneth Jones Criteria for Diagnosing Tuberculous Meningitis in Children. J Coll Physicians Surg Pak 2010;20(4): 258-6I.

9. Baveja $C P$, Gumma $V$, Jain $M$, Choudhary M, Talukdar B,Sharma VK. Newer methods over the conventional diagnostic tests for tuberculous meningitis: do they really help? Trop Doct 2009 39(I):|8-20. DOI: $10.1258 /$ td 2008.080082.

10. Chatterjee S. Brain tuberculomas, tubercular meningitis, and posttubercular hydrocephalus in children. J Pediatr Neurosci $2011 ; 6$ (SuppI I):S96-SI 00. DOI:10.4I03/I8I7-1745.85725.

I I. Nataprawira HM, Ruslianti V, Solek $P$, Hawani D, Milanti M, Anggraeni R, et al. Outcome of tuberculous meningitis in children: the first comprehensive retrospective cohort study in Indonesia. Int J Tuberc Lung Dis 2016;20(7):90914. DOI: | 0.5588/ijtld. I5.0555.

12. Faried A, Putra SPS, Suradj EW, Trianto , Akbar RR, Nugraheni NK, et al. Characteristics and outcomes of pediatric tuberculous meningitis patients with complicated by hydrocephalus with or without tuberculoma at Regional Public Hospital Teluk Bintuni, West Papua, Indonesia. Inter Discip Neurosurg 2020; 19:100609. DOI:10.1016/ j.inat.2019.100609.

13. Syggelou A, Spyridis N, Benetatou K, Kourkouni E, Kourlaba G, Tsagaraki M, et al. BCG Vaccine Protection against TB Infection among Children Older than 5 Years in Close Contact with an Infectious Adult TB Case. J Clin Med $2020 ; 9(10): 3224$. DOI: $10.3390 / \mathrm{jcm} 9103224$.

14. Afridi JK, Dar AS, Karim R, Younas $M$, Khan MA. To determine the accuracy of highly suspected Clinical features for the diagnosis of Tuberculous meningitis. Khyber J Med Sci 20 I 5;8(2): 1 92-6.

15. Van Well GTJ, Paes BF, Terwee CB, Springer P, Roord J], Donald PR, et al. Twenty years of pediatric tuberculous meningitis: a retrospective cohort study in the western cape of South Africa. Pediatrics 2009; I 23(I):el-e8. DOI:10.1542/peds.2008-1353.

16. Rashid A, Arif A, Anwar MW, Ali AS. A Retrospective Review of Tuberculosis among Children Admitted at Tertiary Care Center of Lahore, Pakistan. Pak J Med Health 
Sci 20I8; I2(2):775-7.

17. Qureshi S, Sohaila A, Hannan S, Sheikh MDA, Qamar FN. Comparison of Xpert MTB/RIF with AFB smear and AFB culture in suspected cases of paediatric tuberculosis in a tertiary care hospital, Karachi. J Pak Med Assoc 2019;69(09): 1273-8.

18. Khan IM, Khan S, Laaser U. Tuberculous meningitis: a disease of fatal outcome in children. Eur J Pediatr 2003;162(4):28I-2. DOI: |0.1007/s0043|-003-|| I2-4.

19. Anjum N, Noureen N, Iqbal I. Clinical presentations and outcomes of the children with tuberculous meningitis: An experience at a tertiary care hospital. J Pak Med Assoc 2018;68(I):10-5.

20. Miftode EG, Dorneanu OS, Leca
DA, Juganariu G, Teodor A, Hurmuzache $M$, et al. Tuberculous Meningitis in Children and Adults: A 10-Year Retrospective Comparative Analysis. PLoS One 2015;10(7): e0I33477. DOI:10.137I/journal. pone.0133477.

21. Mihailidou E, Goutaki M, Nanou A, Tsiatsiou O, Kavaliotis J. Tuberculous meningitis in Greek children. Scand J Infect Dis 20 I2;44(5):337-43. DOI: $10.3109 / 00365548.2011 .639030$.

\section{AUTHORS' CONTRIBUTIONS}

Following authors have made substantial contributions to the manuscript as under:

BA: Analysis and interpretation of data, drafting the manuscript, critical review, approval of the final version to be published

SSHS: Conception \& study design, acquisition, analysis and interpretation of data, drafting the manuscript, approval of the final version to be published

Authors agree to be accountable for all aspects of the work in ensuring that questions related to the accuracy or integrity of any part of the work are appropriately investigated and resolved.

\begin{tabular}{|c|}
\hline CONFLICT OF INTEREST \\
Authors declared no conflict of interest \\
GRANT SUPPORT AND FINANCIAL DISCLOSURE \\
NIL \\
\hline
\end{tabular}

DATA SHARING STATEMENT
The data that support the findings of this study are available
from the corresponding author upon reasonable request.

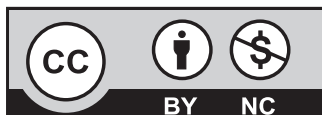

This is an Open Access article distributed under the terms of the Creative Commons Attribution-Non Commercial 2.0 Generic License.

\section{KMUJ web address: www.kmuj.kmu.edu.pk \\ Email address: kmuj@kmu.edu.pk}

